\title{
Research of the Relationship of Criminal Violence, Adult Attachment Styles and Personality Traits of Violent Male Offenders
}

\author{
Laura Simane-Vigante ${ }^{1}$ Mg. psych.; Irina Plotka ${ }^{2}$ Dr. psych.; Nina Blumenau ${ }^{3}$ Dr. sc. Ing. \\ Baltic International Academy, Latvia \\ 1.simane@inbox.lv ${ }^{1}$; irinaplotka@inbox.lv² $\underline{\text { nina.blum@gmail.com }}^{3}$
}

\begin{abstract}
The problem of assessing criminal attitudes towards violence of violent offenders is very essential. It is important to measure criminal attitude using valid procedures as Self-Concept Implicit Association Test (IAT) and also consider its relationship with additional variables as attachment styles and personality traits, that could help to explain the forming and maintaining criminal attitude towards violence. The aim of this study is to research the relationship of criminal violence, adult attachment styles and personality traits of violent male offenders. Six research questions were formed. Participants were violent male prisoners $(N=77)$, aged 20-62 years $(M d n=34$ or $M=35.5, S D=10.6)$. Methods used: Specially designed Self-Concept IAT, measuring implicit criminal attitudes towards violence; Criminal Attitudes to Violence Scale (CAVs); the Eysenck Personality Questionnaire Revised Abbreviated (EPQR-A) and Vulnerable Attachment Style Questionnaire (VASQ). The main results showed that anxious-ambivalent attachment style is more common for violent prisoners. It was found that the greatest impact on implicitly measured attitudes towards criminal violence is made by insecurity then, explicit attitudes towards violence and then by neuroticism. The factor analyses indicated three factors. The results can be used in the process of re-socialization of violent prisoners.
\end{abstract}

Keywords: attitudes towards violence, attachment styles, personality traits, implicit measures, criminal offenders, psychology.

\section{Introduction}

The concept of criminal attitudes has not been widely researched and there are not many valid instruments for its measurement. In the context of the paper, attention is paid to Self-Concept IAT development and its relationship to self-concept procedures. To understand the essence of attitudes towards violence, it is important to consider it through concepts as attachment styles and personality traits.

The attachment theory

The attachment theory was originally developed by J. Bowlby (1984), who defined that attachment, formed in childhood, is underlined by an affectionate bond, a special linkage with the attachment figure, usually a primary caregiver (e.g., mother) (Bowlby, 1988). He developed the attachment theory combining the theories of emotional and cognitive development (Karen, 1994), mainly explaining attachment behaviour as a behaviour that is biologically rooted and is a part of human nature and it is activated when the child is not feeling well or is experiencing any other distressing emotion (fear, anxiety), resulting in proximity seeking (Bowlby, 1988).

Attachment theory was also influenced by ethological theory, which explains the evolution of attachment behaviour that starts at birth, continues for the rest of the person's life. The process is divided in to four phases and each phase has its own input in the development of attachment (Ainsworth et al., 1978). The final two stages (clear cut attachment and goal- corrected partnership) are the most important, because the child starts to demonstrate specific attachment behaviours like separation anxiety (Eisen, Schaefer, 2005). At the same time secure base effect is formed, when the child uses the mother as a base from which to explore the surroundings and always return to, if needed (Bowlby, 1988).

M.D.S Ainsworth expanded J. Bowlby's theory, mainly though her well known experimental tool 'The Strange situation' in 1978, and came to a conclusion that not only biological, but also factors like cultural (the influence of the society and its norms) and individual differences, influences attachment relations (Parkes, Stevenson-Hinde, Marris, 2004). She integrated the results of the experiment in to three attachment styles (secure, anxious- ambivalent and avoidant) (Ainsworth et al., 1978).

The attachment formation can result in to secure or insecure attachment. The security of attachment style is highly dependent on the actions of the attachment figure. To form a secure attachment, the primary caregiver needs to be accessible even if not present, emotionally available and willing to 
respond (Bowlby, 1988). The insecurity of attachment is formed, in situations, when the caregiver fails to provide proximity or practises too demanding parenting style (Bukatko, Daehler, 2012).

Since the beginning, attachment theory had a lifespan approach to human development. Childhood attachment is exchanged in adulthood when the primary attachment figures, parents, are replaced by a different one - a partner (Parkes, Stevenson-Hinde, Marris, 2004). Adult attachment has been defined as: "stable tendency of an individual to seek and maintain proximity to and contact with one or a few specific individuals who provide the subjective potential for physical or/and psychological safety and security" (Berman, Sperling, 1994, 8).

Adult attachment is bi-directional, both partners are the support givers and receivers (Shemmings, 2005). For adults to gain proximity, it is enough to know that their attachment figure is reachable and willing to respond (Hazan, Shaver, 1994). There are important differences between securely, avoidant and anxiously - ambivalently attached adults and the way they solve problems and behave in their romantic relationships (Tucker, Anders, 1998). Securely attached individuals are comfortable with intimacy, trust and have good communication levels. They are supportive and friendly. Avoidant individuals have difficulties with depending on and trusting other people (Feeney, Noller, 1996). Avoidantly attached adults tend to maintain their independence and also have a tendency to stay emotionally distant from their partner, although they also tend to be jealous. Anxious- ambivalent individuals have extreme need for love and closeness, fearing that the partner would not support and abandon them when it is needed. They also experience jealousy (Shaver, Balsky, Brennan, 2000).

Based on the previously mentioned theoretical models, K. Bartholomew developed and explained four attachment styles that are formulated according to the way (positive or negative) a person sees himself and others. Pairing the positive (high) and negative (low) models of self and others, Secure, Preoccupied (extremely dependent), Dismissing (denying) and Fearful (avoidant) attachment styles were defined (Bartholomew, Horowitz, 1991). The current study is based on three adult attachment styles, adjusted by C. Hazan and P.R. Shaver (1994).

\section{The link of attachment styles and criminal violence}

Violence is defined as the most severe type of physical or nonphysical aggression that is likely to cause serious physical or psychological harm (APA Dictionary of Psychology, 2015). Criminal violence is a violent act (usually involving physical violence - the use of physical force, often causing serious injury) that is against the law. Without the law, any kind of most immoral violent action cannot be considered "criminal violence" (Riedel, Welsh, 2011).

According to J. Bowlby, criminal violence is a disorder of the attachment system (Bowlby, 1984). Violence initially could be divided in to affectionate - reaction to a threat (evolutionary basis - selfprotection) and predatory - planned, purposeful and emotionless (evolutionary basis- haunting for food) (Meloy, 1988). More recently researchers have contributed to the theory defining affectionate violence as reaction to anger or fear and the basic characteristics are emotional, reactive, impulsive and expressive (Bushman, Anderson, 2001). Predatory violence is regarded as absence of emotion and threat and is deliberately planned. It is characterized as instrumental and cold-blooded (Woodworth, Porter, 2002).

Proximity seeking has been stated as a link to both types of violent behaviour and attachment system. In predatory violence the offender seeks the victim and the drive of such proximity seeking is destructive. In case of affectionate violence, proximity causes intense defensive reaction that results in to violence (Fonagy et al., 1997).

Analysis of the researches shoved that there is a relationship of attachment styles and criminal violence (Fonagy et al., 1997) as well as other types of violence, for example, intimate partner violence (Higginbotham et al., 2007). The study examined relationship of attachment styles, intimate partner violence and religiosity. The results showed that insecurely attached individuals experienced more violence in their romantic relationships and was likely to be a victim. Securely attached individuals were more satisfied with their relationships and were engaged in more stable and longer-lasting relationships that adapted peaceful and productive conflict resolution (Higginbotham et al., 2007). The results of another study showed that attachment anxiety and dependency, referring to anxious/ambivalent attachment style, provides the link between intimate partner relationship and Post Traumatic Stress Disorder (PTSD) (Scott, Babcock, 2009). It can be concluded that securely attached individuals are not 
prone to predatory violence, they can resolve conflicts in a healthy non-violent manner and also will not suffer from PTSD after violent episodes.

\section{The link of personality and criminal violence}

Researchers have been trying to link personality traits to criminality for a long time (Akers, Sellers, 2012). It has been researched that certain personality traits are connected to antisocial behavior (Miller, Lynam, 2001). These models are: Five factor model (FFM) (McCrae, Costa, 1990), PEN (Psychoticism, Extraversion, neuroticism) model (Eysenck, 1977), Tellegen's three-factor model (Tellegen, 1985), C.R. Cloninger's temperament and character model (Cloninger, Svrakic, Przybeck, 1993).

The current research is based on the PEN model by H.J. Eysenck. To his mind, the criminal should have to provide high scores in all three dimensions of personality. H.J. Eysenck's, on temperament based, theory reflects the influence of bio-social factors on the development of antisocial behaviour and is regarded to as three-factor personality model (Eysenck, 1977).

Individuals, who show high scores in Extraversion (E) scale are characterized as socially active, talkative, and driven by the search of adventures and new experiences. Low E scores indicate low level of arousal, thus more stimulation from the environment is needed. Individuals with high Neuroticism (N) scores suffer from more anxiety, they are more depressive, emotionally unstable and react more to unfavourable stimuli. If the $\mathrm{N}$ score is low, individuals have stable nervous system, that does not overreact on the stimuli of the environment. Individuals with high Psychoticism (P) scores are aggressive, antisocial and egocentric (Eysenck, 1977).

According to the H.J. Eysenck's personality trait theory the link to criminal behaviour has been developed in the process of socialization. He stated criminal behaviour as a delay in development, because criminal behaviour is stated as selfish, and instant gratification, opposite to socialization, because in process of socialization children learn to delay the gratification and be more orientated towards the interest of society not only selfish interests (Eysenck, 1977). Based on the theory of H.J. Eysenck, a hypothesis has been developed: high P, E and $\mathrm{N}$ scores indicates risk of antisocial behaviour.

It has not been yet properly stated exactly which dimension $(\mathrm{P}, \mathrm{E}$ or $\mathrm{N})$ is the most associated to criminal behaviour. For example, G.H. Gudjonsson, J.F. Sigurdsson, S. Young, A.K. Newton (Gudjonsson et al., 2009) discovered that mood swings, that is predicted by $N$ (neuroticism) scale, influence violent behaviour more than antisocial personality traits, as evidenced by $\mathrm{P}$ (psychoticism) scale.

A research measured the influence of different risk factors on violent crime. The sample consisted of two groups - participants, who had a history of violent crime and participants, who didn't have any violent crime reported on them in the past. Each risk factor (personality, family, social support, coping style, impulsiveness and aggression) was assessed. Main findings of the research - groups with young people who have engaged in violent activities in the past scored significantly higher $\mathrm{E}$ and $\mathrm{P}$ rates than non-violent youth groups. With this type of personality (high Extraversion and Neuroticism), young people become nervous, suffer from anxiety and depression. This means that they are more responsive to environmental stimuli and it is more difficult for them to maintain peace. This difficulty can turn in to violent behaviour that leads to committing a crime (Qiu et al., 2014).

Implicit methods as a measurement of attitudes towards criminal violence

The main concept of attitude towards criminal violence (criminal violence) is yet to be concluded. Criminal attitudes have been hypothesed to be criminogenic thinking, distorted cognition, irrational beliefs and antisocial attitudes (Andrews, Bonta, Wormith, 2006).

Up to date only a couple of researches on criminal attitudes or attitudes towards violence using implicit measurement methods have been published and only some of them used violent criminal offenders as a sample (Snowden et al., 2004; Polaschek et al., 2010; Robertson, Murachver, 2007; Eckhardt et al., 2012).

All of the mentioned studies as well as our previous studies have been using Implicit Association Test (IAT) as the main instrument to measure criminal attitudes towards violence. IAT is a cognitivebehavioural paradigm (computerized response latency task) that measures the strength of automatic (implicit) associations between concepts (e.g., 'positive - negative' and 'violence-piece') relying on latency measures in a straightforward categorization task (Greenwald, McGhee, Schwartz, 1998). IAT 
is being considered by many to be the most reliable and valid response latency-based measure that is currently available (De Houwer, De Bruycker, 2007).

There are many variations of the IAT procedure and mostly researchers, who have designed IAT measuring violence and aggression have been focused on classical 7 block IAT (Snowden et al., 2004; Polaschek et al., 2010; Simane-Vigante, Plotka, Blumenau, 2015; Eckhardt, Crane, 2014; Niazi, 2011). Many of them have suggested that for measuring as sensitive issue as attitude towards criminal violence Self-Concept IAT could provide more reliable results. Self-Concept IAT has been adapted to measuring implicit self-concept by observing reaction times for classification tasks in which the concept pair used in the IAT is Self-Other (Greenwald, Farnham, 2000).

The main novelty of the present research is that we do not only measure attitude towards violence as such. This time we add different variables (attachment styles and personality traits) and attempt to explain one of the factors, why the attitude towards violence is formulated and maintained.

The aim of this study is to research the relationship of criminal violence, adult attachment styles and personality traits of violent male offenders.

\section{Methodology}

The six research questions are:

1. Which attachment style is more common for violent offenders?

2. Is there a relationship between vulnerability, insecurity, proximity seeking, violence (measured with implicit measurement methods and self-assessment procedures), personality traits and times of previous convictions?

3. Is there a relationship between attachment styles (secure, anxious, avoidant) and attitudes towards violence and personality traits?

4. What contribution to implicitly estimated attitude towards criminal violence is made by vulnerability and its scales (insecurity and proximity seeking), personality traits, previously sentenced times and the explicitly estimated attitude towards criminal violence?

5. What contribution to explicitly estimated attitude towards criminal violence is made by vulnerability and its scales (insecurity and proximity seeking), personality traits, previously sentenced times and the implicitly estimated attitude towards criminal violence?

6. What common factors underlie the relationship between the results of measurements of the implicit and explicit attitudes towards the violence, vulnerability attachment styles and the personality traits and previously sentenced times of violent criminal offenders?

\section{Participants}

The participants were male prisoners $(N=77)$, aged 20-62 years $(M d n=34$ or $M=35.5, S D=10.6)$, who have been convicted for violent crimes (homicide, murder, assault, manslaughter, sexual assault, rape, robbery) and are undergoing their sentence in a high security prison.

\section{Methods}

\section{Explicit methods:}

There were three explicit methods used, to measure each variable.

To measure criminal violence, a linguistically adapted Criminal Attitudes towards Violence Scale (CAVS) in Latvian and Russian (Polaschek, Collie, Walkey, 2004) was used. The internal consistency of CAVs was Cronbach`s alpha $=0.89$, indicating high internal consistency.

To indicate attachment styles, vulnerable attachment style and its measures- insecurity and proximity seeking, the primary linguistic adaptation of Vulnerable Attachment Style Questionnaire (VASQ) in Latvian and Russian (Bifulco et al., 2003) was used. The internal consistency of VASQ was Cronbach`s alpha $=0.80$, indicating high internal consistency.

To indicate personality traits (Psychoticism, Extraversion and Neuroticism) a linguistically adapted The Eysenck Personality Questionnaire Revised-Abbreviated (EPQR-A) in Latvian and Russian (Francis, Brown, Philipchalk, 1992) was used. The EPQR-A showed acceptable internal consistency (Cronbach`s alpha $=0.70$ ). 


\section{Implicit Method:}

A new Violence Self-Concept Implicit Attitude Test (Self-Concept IAT) procedure was designed with the aim to measure implicit violent attitudes reflecting them on self and others. The procedure was created in Latvian and Russian languages.

The construction of the IAT: Categories "Self" (verbal stimuli) were picked according on the best known (easily understood) words describing the concept of "me" and "others" in both languages.

The pictorial (visual) stimuli were picked according to the most common actions of violence: stabbing, strangling, fighting (hitting), shooting, attacking, violence towards women (intimate partner violence). The visualisations of all but one of the acts are graphic, thus they are not traumatizing, and everyone can use their imagination to create their own view of the situation. Two pictures of weapons (some of the most popular when it comes to acts of violence) - a gun and a knife with blood were also included as the pictorial stimuli in the target categories.

Attributes "Piece" were picked according to actions that are peaceful and do not involve high adrenalin activities (as skiing, parachute jumping), competitive activities (like team sports or boxing) and women (like couple activities, because it could be associated with intimate partner violence).

Because of the uniqueness of the sample (violent criminal offenders), it is necessary to create some modifications to the standard self-concept IAT. As D.L.L. Polaschek with colleagues stated, it is necessary to shorten and simplify the methodology, because often high-risk criminal offenders face problems with head injury, cognitive functioning and learning (Polaschek et al., 2010). As a result, the trail periods were shortened as much as possible, to still maintain the validity of the procedure, but shorten the main duration of the procedure (Table 1).

Apparatus: Certified licensed software E-Prime $2 \circledR$.

\section{Research Procedure}

The researchers wrote an application letter to the Latvian Ministry of Justice and the Latvian Prison Administration, where the research was reviewed and authorized. The research took place in Brasa Prison and Liepaja Prison. All the participants took part in the research voluntarily, they were assured that that the research has no connection with their sentence or the possibility of probation and the participation is anonymous. The research was conducted individually. Participants completed the tasks in the same order: Self-Concept IAT measure and explicit measures. The prisoner was asked to write down how many times has he been sentenced previously and what criminal codes has he been sentenced by. The researcher thanked the prisoner for participation and answered all the questions, if he had any. It took about two weeks to gather all the data. After analysing the data, the interested employees from the prisons and the Latvian Prison Administration were invited for a seminar, to introduce them with the gained results.

Self-Concept IAT measure. The authors designed the experimental procedure Self-Concept IAT, using seven trial blocks. Performance of the implicit method took an average of 10 to 20 minutes. Participant's reaction time (RT) was registered. Each stage was preceded by a set of instructions concerning the dimensions of the categorization task and the appropriate key responses. Instructions were written in black letters on a white background and located in the centre of the screen. Each sentence began with a new line. Each target word appeared cantered on the screen. All target and category words were presented in lowercase letters. Before the start of the experiment, on a computer monitor a participant was given general instructions and specific instructions before each of the blocks (tasks). The task of the participants was the differentiation of presented stimuli. The violence Self-Concept-IAT combined verbal and visual stimulus ( 6 pictures with violence theme, covering different types of physical violence and 6 pictures with the piece theme, covering different types of peaceful actions preferred by men (e.g., fishing, boating, playing with children). Stimulus word displayed on the screen without auditory accompaniment and remained on the screen until the pressing a key of the participant (Table 1). The RT for each trail was recorded as the time interval between the onset of stimulus presentation and pressing the correct key. Words were selected randomly without replacement.

To ensure the internal validity of the experiment the main parameters were unchanged (the time of stimulus presentation, the intervals between stimuli, number of stimuli - the words, the font, chromatic background settings). 
Table 1

Violence Self-Concept IAT

\begin{tabular}{|c|c|c|c|c|}
\hline Block & Trials & Function & Left-key response "Q" & Right- key response "P" \\
\hline 1 & 10 & Practice & $\mathrm{Me}(\mathrm{w})$ & Others (w) \\
\hline 2 & 15 & Practice & Violence (v) & Peace (v) \\
\hline 3 & 40 & Test & $\mathrm{Me}(\mathrm{w})+$ Violence $(\mathrm{v})$ & Others(w)+Peace (v) \\
\hline 4 & 45 & Test & $\mathrm{Me}(\mathrm{w})+$ Violence $(\mathrm{v})$ & Others(w)+Peace (v) \\
\hline 5 & 20 & Practice & Others(w) & $\operatorname{Me}(w)$ \\
\hline 6 & 40 & Test & Others $(\mathrm{w})+$ Violence $(\mathrm{v})$ & $\mathrm{Me}(\mathrm{w})+$ Peace $(\mathrm{v})$ \\
\hline 7 & 45 & Test & Others $(\mathrm{w})+$ Violence $(\mathrm{v})$ & $\operatorname{Me}(\mathrm{w})+$ Peace $(\mathrm{v})$ \\
\hline
\end{tabular}

Note. $v$-visual category, $w$-verbal category.

\section{Results and Discussion}

Variables. The following variables were used:

$D(I A T), D$ - implicit associations towards violence. $D \geq 0.15$ indicated implicit preference of violence, $D \leq-0.15$ - implicit preference of non-violence (meaning - peace), $-0.15<D<0.15$ - no effect. We revealed that $6 \%$ of participants have implicit preference of violence and $79 \%$ have implicit preference of non-violence, which corresponds to previous researches, where IAT procedure has been used on violent criminals (Polaschek et al., 2010; Snowden et al., 2004).

$C A V s$ - the strength of explicit criminal attitude towards violence. Quartiles are $Q_{1}=38.5, Q_{3}=61$. If $C A V s \leq 38.9$ the level of explicit attitude towards violence is low, if $C A V s \geq 61$ - high.

Vulnerability - (Vulnerability $\geq 57$ high, Vulnerability $<57$ low). Two scales: Insecurity (Insecurity $>30$ high, Insecurity $\leq 30$ low) and Proximity Seeking - (Proximity Seeking $\geq 27$ high, Proximity Seeking < 27 low).

Attachment Styles (Figure 1): Secure Style (Insecurity $\leq 30$ ), Insecure Anxious Style (Insecurity - > 30 and Proximity Seeking $\geq 27$ ), Insecure Avoidant Style (Insecurity - > 30 and Proximity Seeking <27),

Psychoticism, Neuroticism, Extraversion.

Age, Previously Sentenced (times)- how many times the participant has been previously sentenced, Previously Imprisonment (times) - how many times the participant has concluded a prison sentence before the present, waiting at home- is there someone waiting for him at home.
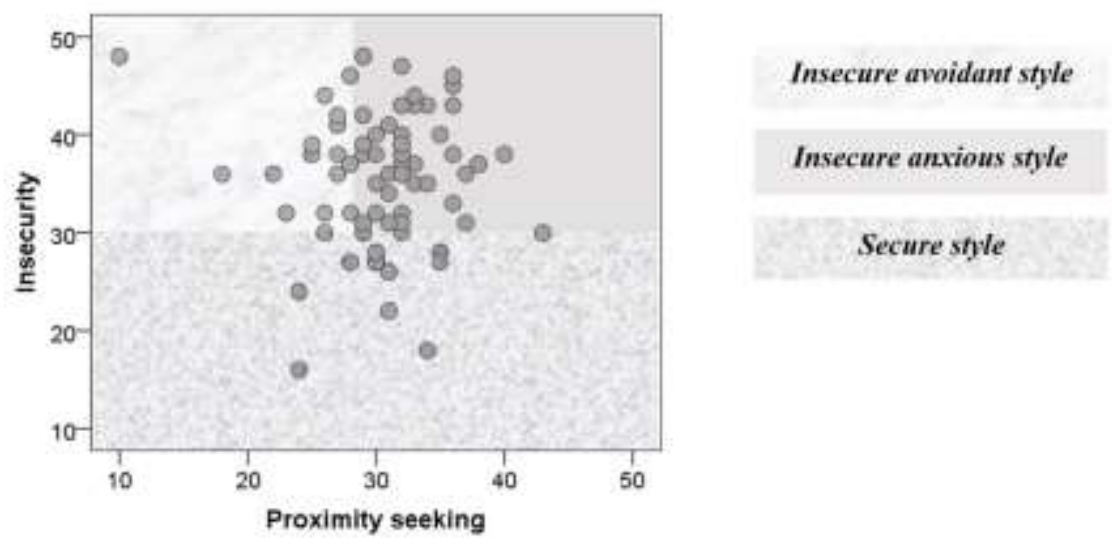

Figure 1. Attachment styles: scatter.

The study of the data showed that the data distribution allows the use of parametric statistics methods. Methods of statistical data processing were chosen in accordance with the research questions.

To answer the first research question "Which attachment style is more common for violent offenders?" a frequency analyses: "Fisher's angular transformation $\varphi^{*}$-test" was used. 


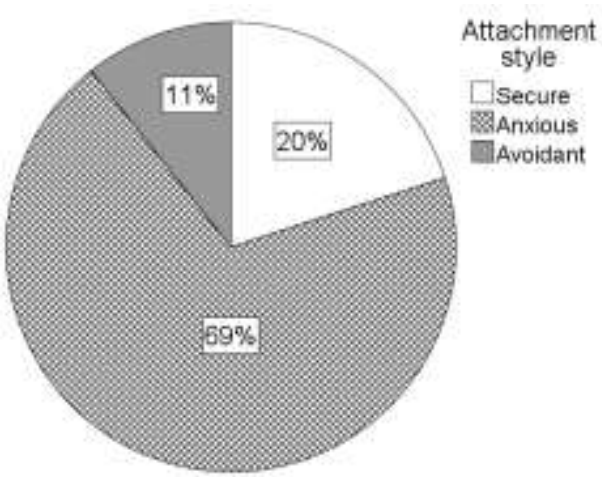

Figure 2. Attachment styles for two groups.

The proportion of prisoners with an anxious-ambivalent attachment style (69\%) statistically significantly exceeds the proportion of prisoners with secure attachment style (11\%) and avoidant attachment style (20\%): $\left(\varphi *=7.98\right.$; two-tailed, effect size $=1.30$, large and $\varphi^{*}=6.37$; two-tailed, effect size $h=1.04$, large), respectively (Figure 2 ).

Table 2

$\varphi$ *- test: "Fisher's angular transformation". Attachment Style.

Effect size $h=\left|\varphi_{1}-\varphi_{2}\right|(0.2$ - low, 0.5 - medium, 0.8 - large $)$

\begin{tabular}{|l|l|c|c|c|c|c|c|c|c|c|c|c|}
\hline \multicolumn{1}{|c|}{$\mathbf{2}$} & $\boldsymbol{2}$ & $\boldsymbol{k}_{\mathbf{1}}$ & $\boldsymbol{k}_{\mathbf{2}}$ & $\boldsymbol{n}_{\mathbf{1}}$ & $\boldsymbol{n}_{\mathbf{2}}$ & $\boldsymbol{p}_{\mathbf{1}}$ & $\boldsymbol{p}_{\mathbf{2}}$ & $\boldsymbol{\varphi}_{\mathbf{1}}$ & $\boldsymbol{\varphi}_{\mathbf{2}}$ & $\boldsymbol{\varphi}^{*}$ & $\boldsymbol{h}$ & $\boldsymbol{p}$ \\
\hline Secure & Anxious & 15 & 52 & 75 & 75 & 20.00 & 69.33 & 0.93 & 1.97 & $\mathbf{6 . 3 7}$ & 1.04 & 0.000 \\
\hline Secure & Avoidant & 15 & 8 & 75 & 75 & 20.00 & 10.67 & 0.93 & 0.67 & 1.60 & 0.26 & 0.11 \\
\hline Anxious & Avoidant & 52 & 8 & 75 & 75 & 69.33 & 10.67 & 1.97 & 0.67 & $\mathbf{7 . 9 8}$ & 1.30 & 0.000 \\
\hline
\end{tabular}

Note. $k_{\mathrm{i}}$ - the number of participants with the researched effect from group with size $n_{\mathrm{i}}, i=1 ; 2$, $p_{i}=\frac{k_{i}}{n_{i}} \cdot 100 \%, \varphi_{i}=2 \arcsin \sqrt{p_{i} / 100}, \varphi^{*}=\left|\varphi_{1}-\varphi_{2}\right| \sqrt{\frac{n_{1} n_{2}}{n_{1}+n_{2}}}$ - Fisher's angular transformation test, $h=\left|\varphi_{1}-\varphi_{2}\right|$ - effect size (Cohen, 1988, p.181), $p$-value for statistic $\varphi^{*}$ (normal distribution, $\mu=0$, $\sigma=1)$, two-tailed, $H_{0}: \mathrm{p}_{1}$ and $\mathrm{p}_{2}$ have a random difference.

Data shows that anxious-ambivalent attachment style is more common for violent prisoners. D. Dutton (Dutton, Golant, 1995; Dutton, 2006) found that the majority of male offenders, who have committed a crime of domestic violence, have insecure attachment. Approximately $40 \%$ of the individuals have anxious- ambivalent attachment style. It has been stated that individuals, who have anxious- ambivalent attachment style suffer from extreme jealousy and fear to lose the partner (Shaver, Balsky, Brennan, 2000). Jealousy, insecurity and inability to manage conflicts in a healthy manner can trigger violence.

To answer the second research question "Is there a relationship between vulnerability, insecurity, proximity seeking, violence (measured with implicit measurement methods and self-assessment procedures), personality traits and times of previous convictions?" correlation coefficients Pearson $(r)$ and Spearman $\left(r_{\mathrm{S}}\right)$ were used. The results are shown in the Table 3 and Figure 3.

There were correlations found between the scales of VASQ and EPQR-A. Between Vulnerability and Neuroticism, a positive correlation was found and between Vulnerability and Extroversion, a negative correlation relationship is found (high vulnerability relates to high neuroticism and high vulnerability relates to low extroversion (thus, introversion) and vice versa). Between Insecurity and Neuroticism a positive correlation was found. There is a negative correlation between Insecurity and Extroversion indicating that introvert people tend to be more insecure and vice versa. Between Proximity Seeking and Psychoticism a tendency to negative correlation was found. These findings partly correspond to the theory (Eysenck, 1977; Fonagy et al., 1997). A positive correlation is found between Vulnerability and Insecurity and between Vulnerability and Proximity seeking. 
A relationship was found between factors of VASQ and attitudes towards criminal violence. Between Vulnerability and $C A V s$ a positive correlation was found indicating that explicit pro-violence attitudes have a relationship with high level of vulnerability.

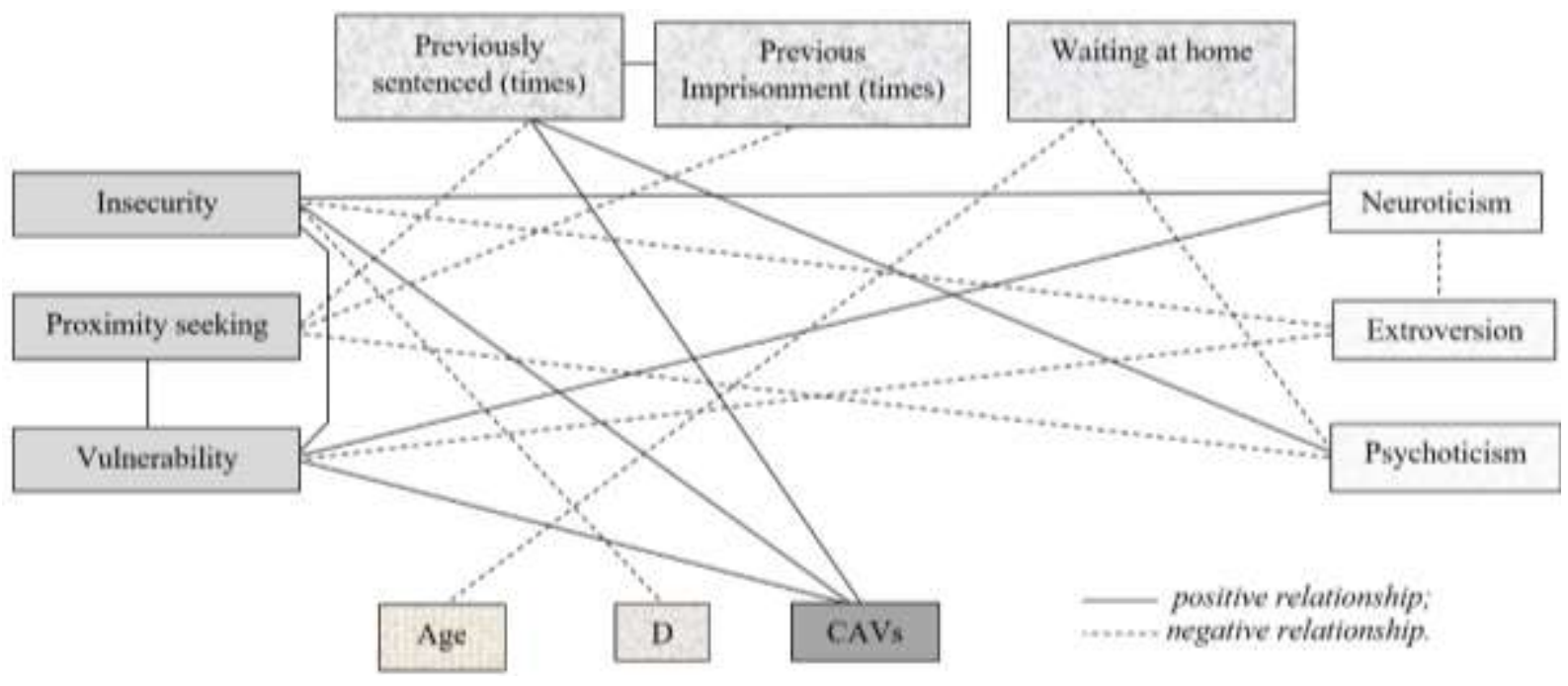

Figure 3. Relationships' diagram.

There is a negative correlation between Insecurity and $D(I A T)$, but a positive correlation between Insecurity and $C A V s$. Low insecurity (indicating security) corresponds to implicitly measured pro-violence attitude. On the other hand, high insecurity corresponds to explicitly measured pro violence attitude. Meaning that even individuals with secure attachment style can have implicit pro-violence attitudes, but they will not admit them. The fact that it was a sample of violent prisoners confirms to the results.

Table 3

Pearson's and Spearman's correlation coefficients (for $p<0.10$ ).

Effect size $\boldsymbol{r}(0.1$ - low, 0.3 - medium, 0.5 - large $)$

\begin{tabular}{|l|l|c|}
\hline \multicolumn{1}{|c|}{ Variable 1 } & \multicolumn{1}{c|}{ Variable 2 } & Sentenced \\
\hline Age & Waiting at home & $r_{\mathrm{S}}(71)=-0.26, p=0.030$ \\
\hline$D$ & Insecurity & $r_{\mathrm{S}}(75)=-0.24, \mathrm{p}=0.039$ \\
\hline Previously sentenced & Previous Imprisonment & $r_{\mathrm{S}}(71)=0.70, p<0.001$ \\
\hline Previously sentenced & CAVs & $r(71)=0.29, p=0.016$ \\
\hline Previously sentenced & Proximity seeking & $r(69)=-0.20, p=0.095$ \\
\hline Previously sentenced & Psychoticism & $r(70)=0.35, p=0.003$ \\
\hline Previous imprisonment & Proximity seeking & $r(69)=-0.20, p=0.070$ \\
\hline Waiting at home & Psychoticism & $r_{\mathrm{S}}(70)=-0.21, p=0.075$ \\
\hline CAVs & Vulnerability & $r(75)=0.25, p=0.029$ \\
\hline CAVs & Insecurity & $r(75)=0.25, p=0.031$ \\
\hline Vulnerability & Insecurity & $r(75)=0.81, \mathrm{p}<0.001$ \\
\hline Vulnerability & Proximity seeking & $r_{\mathrm{S}}(75)=0.58, \mathrm{p}<0.001$ \\
\hline Vulnerability & Neuroticism & $r_{\mathrm{S}}(74)=0.43, \mathrm{p}<0.001$ \\
\hline Vulnerability & Extroversion & $r_{\mathrm{S}}(74)=-0.33, p=0.005$ \\
\hline Insecurity & Neuroticism & $r_{\mathrm{S}}(74)=0.53, p<0.001$ \\
\hline Insecurity & Extroversion & $r_{\mathrm{S}}(74)=-0.36, p=0.002$ \\
\hline Proximity seeking & Psychoticism & $r(74)=-0.19, p=0.099$ \\
\hline Neuroticism & Extroversion & $r(76)=-0.34, p=0.003$ \\
\hline
\end{tabular}

To answer the third research question "Is there a relationship between attachment styles (secure, anxious, avoidant) and attitudes towards violence and personality traits?" one-way ANOVA, Post Hoc test - Scheffe were used. The results are shown in the Table 4 and Figures 4-9. 
Table 4

Relationship between Attachment Styles and D(IAT), CAVs, Insecurity, Proximity seeking, Neuroticism, Psychoticism and Extraversion among sentenced Effect size $\eta^{2}(0.01$ - low, 0.06 - medium, 0.14 - large $)$

\begin{tabular}{|c|c|c|c|}
\hline \multicolumn{2}{|r|}{ Variables } & Sentenced & Effect size \\
\hline 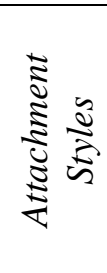 & $\begin{array}{l}D(\text { IAT }) \\
\text { CAVs } \\
\text { Neuroticism } \\
\text { Psychoticism } \\
\text { Extraversion } \\
\text { Previously sentenced }\end{array}$ & $\begin{array}{l}F(2,72)=1.20, \mathrm{p}=0.31, \eta^{2}=0.032, \mathrm{~ns} \\
F(2,72)=1.93, \mathrm{p}=0.15, \eta^{2}=0.051, \mathrm{~ns} \\
F(2,71)=10.0, \mathrm{p}<0.001, \eta^{2}=0.22 \\
F(2,71)=0.19, \mathrm{p}=0.83, \eta^{2}=0.005, \mathrm{~ns} \\
F(2,71)=4.46, \mathrm{p}=0.015, \eta^{2}=0.11 \\
F(2,66)=1.11, \mathrm{p}=0.337, \eta^{2}=0.032\end{array}$ & $\begin{array}{l}\text { Low (Figure 4). } \\
\text { Low (Figure 5). } \\
\text { Large (Figure 6) } \\
\text { No effect (Figure 7) } \\
\text { Medium (Figure 8) } \\
\text { Low (Figure 9) }\end{array}$ \\
\hline
\end{tabular}

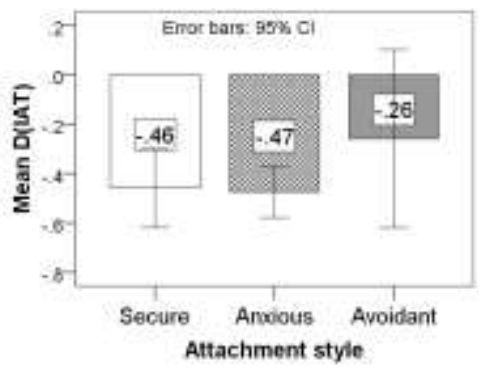

Figure 4. Means of D for Attachment styles.

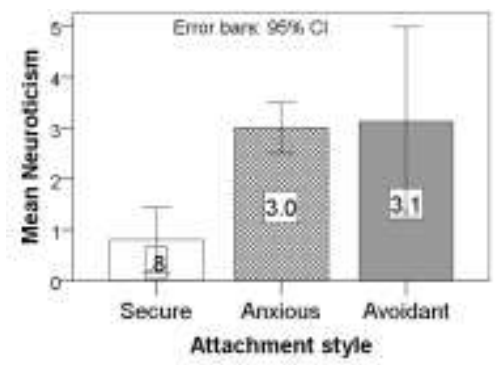

Figure 6. Means of Neuroticism for Attachment styles.

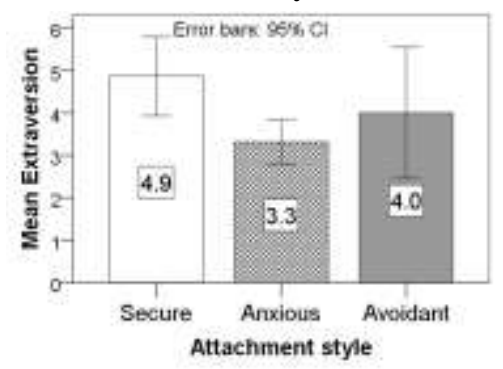

Figure 8. Means of Extraversion for Attachment styles.

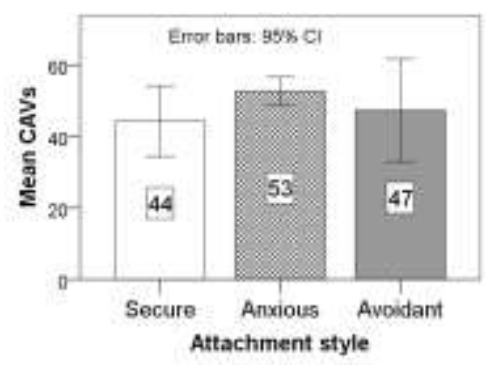

Figure 5. Means of CAVs for Attachment styles.

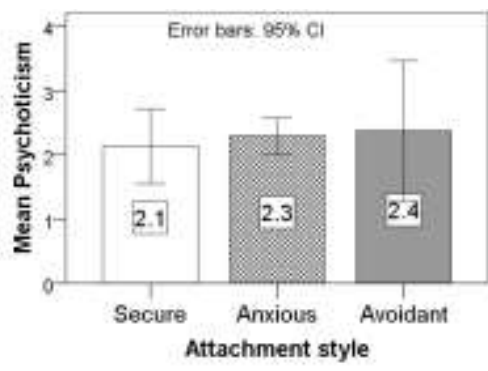

Figure 7. Means of Psychoticism for Attachment styles.

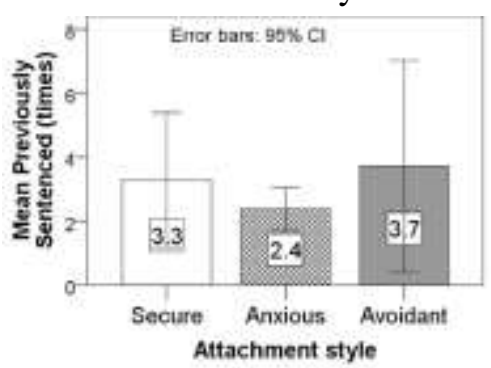

Figure 9. Means of Previously sentenced times for Attachment styles.

The relationships between Attachment Style and Neuroticism, Extraversion were revealed. Namely: the means of Neuroticism in the groups with Anxious and Avoidant Attachment Styles exceed the mean of Neuroticism in the group with Secure Attachment Style. Effect size is large (Figure 6).

The mean of Extraversion in the group with Secure Attachment Style exceeds the mean of Extraversion in the group with Anxious Attachment Style. Effect size is medium (Figure 8).

The relationships without statistical significance are revealed.

- The means of $D(I A T)$ in the groups with Secure and Anxious Attachment Styles exceed the mean of $D(I A T)$ in the group with Avoidant Attachment Style. Effect size is low (Figure 4). 
- The mean of $C A V s$ in the group with anxious attachment style exceeds the mean of $C A V s$ in the group with Avoidant Attachment Style, which exceeds the mean of CAVs in the group with Secure Attachment Style. Effect size is low (Figure 5).

- The mean of Previously Sentenced Times in the group with Avoidant Attachment Style exceeds the mean of Previously Sentenced Times in the group with Secure Attachment Style, which exceeds the mean of Previously Sentenced Times in the group with Anxious Attachment Style. Effect size is low (Figure 9).

To answer the fourth research question "What contribution to implicitly estimated attitude towards criminal violence is made by vulnerability and its scales (insecurity and proximity seeking), personality traits, previously sentenced times and the explicitly estimated attitude towards criminal violence?" it was necessary to research the contribution of independent variables CAVs, Vulnerability, Insecurity, Proximity Seeking, Neuroticism, Psychoticism, Extraversion and Previously Sentenced Times to the dependent variable $D(I A T)$, the multiple regression analysis was used.

Method "Backward". The equation for estimations:

$D($ IAT $)($ estimate $)=-0.150+0.005 * C A V s-0.020 *$ Insecurity $+0.044 *$ Neuroticism.

*multiplication sign

The impact of each independent variable defines by "Beta-coefficients" $(\beta)$. The Beta coefficients are the coefficients in standardized regression equation.

The greatest impact on $D(I A T)$ is made by the variable Insecurity $\left(\beta_{1}=-0.377, p=0.012\right)$ then, by $C A V s$ $\left(\beta_{2}=0.238, p<0.059\right)$ and then by Neuroticism $\left(\beta_{3}=0.234, p=0.097\right)$.

$R$-Square $=0.116$ shows, that $11.6 \%$ of variability of the dependent variable $D(I A T)$ is due to the influence of the independent variables Insecurity, $C A V s$ and Neuroticism. Adjusted $R$-square $=0.075$. Standard error of estimate is 0.35. The result of ANOVA is: $F(3,64)=2.81, p=0.047$.

The greatest impact on $D(I A T)$ is made by the variable Insecurity then, by $C A V s$ and then by Neuroticism. Insecurity contribution to $D(I A T)$ is negative. It corresponds to the correlations gained.

To answer the fifth research question "What contribution to explicitly estimated attitude towards criminal violence is made by vulnerability and its scales (insecurity and proximity seeking), personality traits, previously sentenced times and the implicitly estimated attitude towards criminal violence?" it was necessary to research the contribution of independent variables $D(I A T)$, Vulnerability, Insecurity, Proximity Seeking, Neuroticism, Psychoticism, Extraversion and Previously Sentenced Times to the dependent variable $C A V s$, the multiple regression analysis was used.

Method "Backward". The equation for estimations:

$C A V s($ estimate $)=23.630+9.904 * D($ IAT $)+0.755^{*}$ Insecurity $+1.612 *$ Previously Sentenced Times.

The greatest impact on CAVs is made by the variable Insecurity $\left(\beta_{1}=0.336, p=0.004\right)$ then, by Previously Sentenced Times $\left(\beta_{2}=0.286, p=0.012\right)$ and then by $D(I A T)\left(\beta_{3}=0.228, p=0.047\right)$.

$R$-Square $=0.219$ shows, that $21.9 \%$ of variability of the dependent variable $C A V s$ is due to the influence of the independent variables Insecurity, $D(I A T)$ and Previously Sentenced Times. Adjusted $R$-square = 0.183. Standard error of estimate is 14.24. The result of ANOVA is: $F(3,64)=6.00, p=0.001$.

The greatest impact on $C A V s$ is made by the variable Insecurity then, by Previously Sentenced Times and then by $D(I A T)$. Insecurity contribution to $C A V s$ is positive. It corresponds to the correlations gained.

To answer the sixth research question "What common factors underlie the relationship between the results of measurements of the implicit and explicit attitudes towards the violence, vulnerability attachment styles and the personality traits and previously sentenced times of violent criminal offenders?" a set of variables were selected: D (IAT), CAVs, Vulnerability, Insecurity, Proximity Seeking, Neuroticism, Psychoticism, Extraversion, Previously Sentenced Times, and a factor analyses was applied (Principal Component Method, Rotation Varimax, total variance explained 61\%, three factors). Rotation of the reduced matrixes led to the isolation of three factors (Table 5, Figure 10-13), named "VIN" (Vulnerability-Insecurity-Neuroticism), "PPP" (Previously Sentenced-Psychoticism Proximity Seeking) and "Attitude towards violence". 
The first component "VIN" includes variables Vulnerability, Insecurity and Neuroticism (Table 5; Figure $10,11,12)$. All three factors have been linked by researchers to psychological disorders, mainly depression. It was hypothised that personality trait - neuroticism combined with poor support indicated by high vulnerability and insecurity scores provide best known model for depressive disorder, because it suggests an input from social environment and psychological factors (Brown, Bifulco, Andrews, 1990).

Table 5

Rotated Component Matrix ${ }^{a}$

\begin{tabular}{|c|c|c|c|}
\hline & \multicolumn{3}{|c|}{ Component } \\
\cline { 2 - 4 } & 1 & 2 & 3 \\
\hline Vulnerability & 0.916 & & \\
\hline Insecurity & 0.887 & & \\
\hline Neuroticism & 0.683 & & \\
\hline Extraversion & & & \\
\hline Previously Sentenced (times) & & 0.788 & \\
\hline Psychoticism & & 0.707 & \\
\hline Proximity seeking & & -0.556 & \\
\hline D(IAT) & & & 0.801 \\
\hline CAVs & & & 0.632 \\
\hline
\end{tabular}

a Extraction Method: Principal Component Analysis. Rotation Method: Varimax with Kaiser Normalization.

The second component is called "PPP", it includes variables Previously Sentenced times, Psychoticism and Proximity Seeking with a minus sign (Table 5; Figure 10, 12, 13). According to the results, a high number of previous sentences, high psychoticism scores, which are common in individuals, who are aggressive, antisocial and egocentric (Eysenck, 1977) and low level of proximity seeking, are connected.

The third component is called "Attitude towards violence" (Table 5; Figure 10, 11, 13), which is interesting, because it includes implicitly and explicitly measured attitudes towards violence, although there was no correlation found (Figure 3.). The fact that this factor was formed shows that the specially designed Self-Concept IAT measures attitudes towards criminal violence as CAVs does.

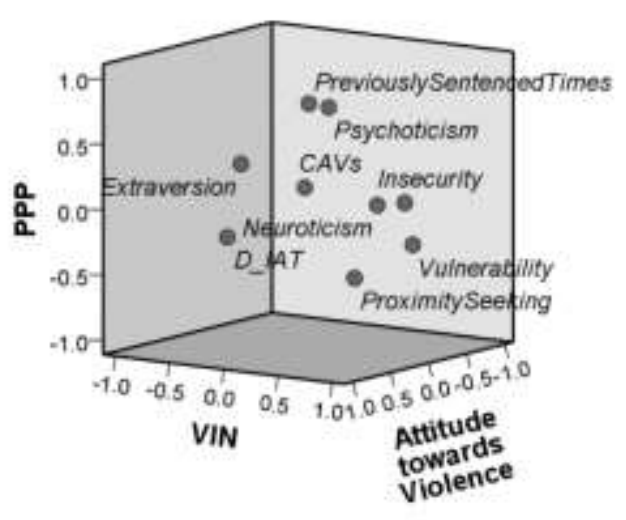

Figure 10. Components' "VIN", "PPP" and "Attitude towards Violence" Plot in Rotated Space.

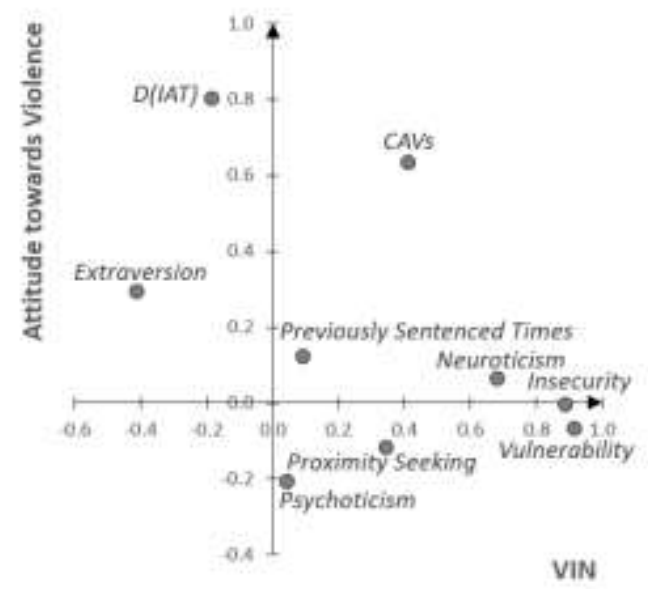

Figure 11. Components" "VIN" and "Attitude towards Violence" Plot in Rotated Space. 


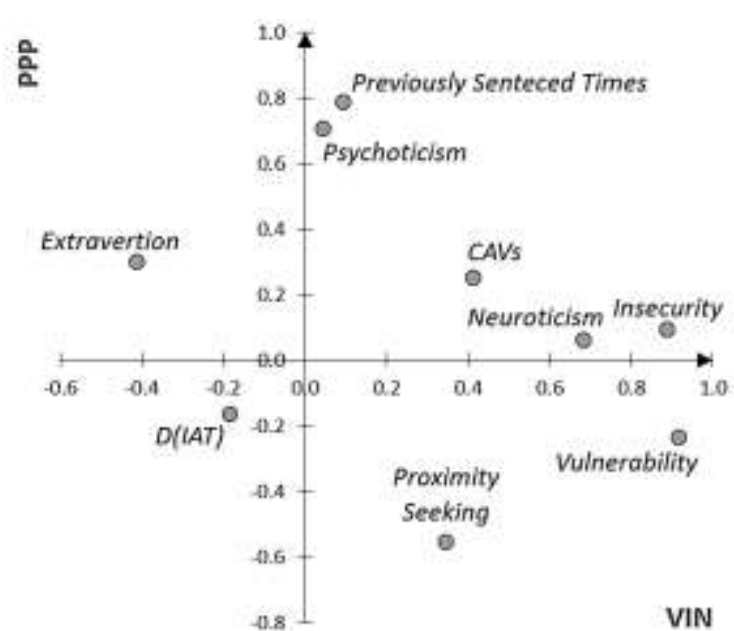

Figure 12. Components" "VIN" and "PPP" Plot in Rotated Space.

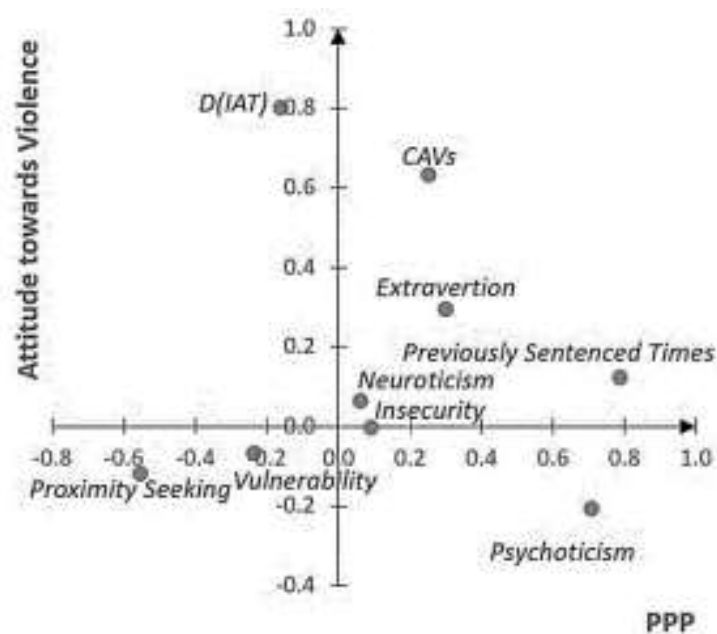

Figure 13. Components" "PPP" and "Attitude towards Violence" Plot in Rotated Space.

\section{Conclusions}

In the theoretical background attachment theory leading to adult attachment styles in the connection of criminal violence was analysed, as well as personality theories and the relationship of personality traits and criminal violence. It was stated that both - attachment and personality trait - theories are biologically based, at the same time they are influenced by social factors. The studies showed that insecure attachment styles (avoidant, anxious ambivalent) are connected to criminal violence and high levels of neuroticism, psychoticism and extraversion are also connected to criminal violence.

To measure implicit attitudes towards criminal violence, specially designed Self-Concept Implicit Attitude Test was constructed for the present research. Both pictorial (visual) and verbal stimuli were used. Categories- self and others (verbal stimuli) and attributes- criminal violence and peace (visual stimuli). To measure attachment styles, personality traits and explicit attitudes towards violence selfreport procedures were used. The sample of the study consisted of violent criminal offenders undergoing their sentence in high-security prisons in Latvia.

The results showed that anxious-ambivalent attachment style is more common for violent prisoners. It was found that high vulnerability rates are related to high neuroticism and high vulnerability relates to low extroversion (thus, introversion) and vice versa. It was found that introvert people tend to be more insecure and vice versa. Between Proximity Seeking and Psychoticism, a tendency to negative correlation was found. The results also showed that explicit pro-violence attitudes have a relationship with high level of vulnerability.

It was found that the greatest impact on implicitly measured attitudes towards criminal violence is made by the variable Insecurity then, by $C A V s$ and then by Neuroticism. The greatest impact on explicitly measured attitudes towards criminal violence is made by the variable Insecurity then by Previously Sentenced Times and then by D(IAT). Factor analyses indicated three factors named "VIN" (Vulnerability-Insecurity-Neuroticism), "PPP" (Previously Sentenced-Psychoticism -Proximity Seeking) and "Attitude towards violence".

The results can be used in the process of re-socialization by prison psychologists working with violent prisoners, in understanding why the criminal attitudes are formed that leads criminals to violent behaviour.

\section{Bibliography}

1. Ainsworth M.D.S., Blehar M.C., Waters E., Wall S. (1978). Patterns of Attachment: A Psychological Study of the Strange Situation. Hillsdale. NJ: Lawrence Erlbaum Associates.

2. Akers R.L., Sellers C.S. (2012). Criminological Theories: Introduction, Evaluation, and Application. New York: Oxford University Press.

3. Andrews D.A., Bonta J., Wormith J.S. (2006). The Recent Past and Near Future of Risk and/or Need Assessment. Crime and Delinquency, 52, 7-27. 


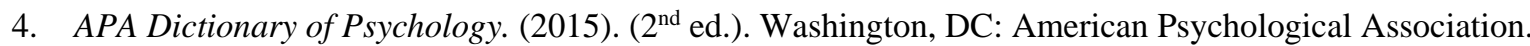

5. Bartholomew K., Horowitz L.M. (1991). Attachment Styles Among Young Adults: A Test of a FourCategory Model. Journal of Personality and Social Psychology, 61(2), 226-244. Retrieved from http://citeseerx.ist.psu.edu/viewdoc/download?doi=10.1.1.332.3652\&rep=rep1\&type=pdf

6. Berman W.H., Sperling M.B. (1994). The Structure and Function in Adult Attachment. In M.B. Sperling, W.H. Berman (Eds.) Attachment in adults: Clinical and developmental perspectives. New York: Guilford, 3-28.

7. Bifulco A., Mahon J., Kwon J.H., Moran P.M., Jacobs C. (2003). The Vulnerable Attachment Style Questionnaire (VASQ): An Interview-based Measure of Attachment Styles that Predict Depressive Disorder. Psychological Medicine, 33(6), 1099-1110.

8. Bowlby J. (1984). Violence in the Family as a Disorder as the Attachment and Caregiving Systems, American Journal of Psychology, 44(1), 9-27.

9. Bowlby J. (1988). A Secure Base: Parent-child Attachment and Healthy Human Development. New York: Basic Books.

10. Brown G.W., Bifulco A.T., Andrews B. (1990). Self-esteem and Depression: III. Aetiological Issues. Social Psychiatry and Psychiatric Epidemiology, 25(5), 235-243.

11. Bukatko D., Daehler M.W. (2012). Child Development: A Thematic Approach. (6 ${ }^{\text {nd }}$ ed.). Boston: Houghton Mifflin and Company.

12. Bushman B.J., Anderson C.A. (2001). Media Violence and the American Public: Scientific Facts versus Media Misinformation, American Psychologist, 56(6/7), 477-489. Retrieved from http://citeseerx.ist.psu.edu/viewdoc/download?doi=10.1.1.486.8914\&rep=rep1\&type=pdf

13. Cloninger C.R., Svrakic D.M., Przybeck T.R. (1993). A Psychobiological Model of Temperament and Character, Archives of General Psychiatry, 50(12), 975-990.

14. Cohen, J. (1988). Statistical power analysis for the behavioral sciences. (2nd ed.). Hillsdale, NY: Lawrence Earlbaum Associates.

15. De Houwer J., De Bruycker E. (2007). Implicit Attitudes towards Meat and Vegetables in Vegetarians and Nonvegetarians. International Journal of Psychology, 42(3), 158-165.

16. Dutton D. (2006). The abusive personality: Violence and control in intimate relationships. New York: Guilford Press.

17. Dutton D., Golant S. (1995). The Batterer: A Psychological Profile. New York: Basic Books.

18. Eckhardt C.I., Crane A.A. (2014). Male Perpetrators of Intimate Partner Violence and Implicit Attitudes toward Violence: Associations with Treatment Outcomes. Cognitive Therapy and Research, 38(3), 291-301.

19. Eckhardt C.I., Samper R., Suhr L., Holtzworth-Munroe A. (2012). Implicit Attitudes toward Violence Among Male Perpetrators of Intimate Partner Violence: A Preliminary Investigation, Journal of Interpersonal Violence, 27(3), 471-491.

20. Eisen A.R., Schaefer C.E. (2005). Separation Anxiety in Children and Adolescence. An Individualized Approach to Assessment and Treatment. New York: Guilford Press.

21. Eysenck H.J. (1977). Crime and Personality. ( $3^{\text {rd }}$ ed.). London: Routledge and Kegan Press.

22. Feeney J.A., Noller P. (1996). Adult Attachment. Thousand Oaks: SAGE Publications.

23. Fonagy P., Target M., Steele M., Steele H. (1997). The Development of Violence and Crime as it Relates to Security of Attachment. In J. D. Osofsky (Ed.), Children in a Violent Society. New York: Guilford Press, 150-177.

24. Francis L.J., Brown L.B., Philipchalk R. (1992). The Development of an Abbreviated form of the Revised Eysenck Personality Questionnaire (EPQR-A): Its Use Among Students in England, Canada, the USA and Australia. Personality and Individual Differences, 13, 443-449.

25. Greenwald A.G., Farnham S.D. (2000). Using the Implicit Association Test to Measure Self-Esteem and Self-concept. Journal of Personality and Social Psychology, 79(6), 1022-1038.

26. Greenwald A.G., McGhee D.E., Schwartz J.K.L. (1998). Measuring Individual Differences in Implicit Cognition: The Implicit Association Test. Journal of Personality and Social Psychology, 74(6), 1464-1480.

27. Gudjonsson G.H., Sigurdsson J.F., Young S., Newton A.K., Peersen M. (2009). Attention Deficit Hyperactivity Disorder (ADHD). How do ADHD symptoms relate to personality among prisoners? Personality and Individual Differences, 47(1), 64-68.

28. Hazan C., Shaver P.R. (1994). Attachment as an Organizational Framework for Research on Close Relationships. Psychological Inquiry, 5(1), 1-22. Retrieved from http://apegosposibles.com/sites/default/files/hazanandshaver.pdf

29. Higginbotham B.J., Ketring S.A., Hibbert J., Wright D.W., Guarino A. (2007). Relationship Religiosity, Adult Attachment Styles, and Courtship Violence Experienced by Females. Journal of Family Violence, 22, 55-62. Retrieved from http://www.alabamamarriage.org/documents/research/nonahmreipublications/ketring/3.pdf

30. Karen R. (1994). Becoming Attached: First Relationships and How They Shape Our Capacity to Love. New York: Oxford University Press.

31. McCrae R.R., Costa P.T. (1990). Personality in Adulthood. New York: Guilford Press.

32. Meloy J.R. (1988). The Psychopathic Mind: Origins, Dynamics, and Treatment. Northvale, NJ: Jason Aronson. 
33. Miller J.D., Lynam D. (2001). Structural Models of Personality and Their Relation to Antisocial Behavior: A Meta-Analytic Review. Criminology, 39(4), 765-798.

34. Niazi A.M. (2011). Effect of Music Tempo in First-Person Shooter on Arousal and Aggression. The Netherlands: Figshare. Retrieved from: https://figshare.com/articles/Effect_of_music_tempo_in_FirstPerson_Shooter_on_arousal_and_aggression/5113537

35. Parkes C.M., Stevenson-Hinde J., Marris P. (2004). Attachment Across the Life Cycle. London: Taylor and Francis e-Library.

36. Polaschek D.L.L., Bell R.K., Calvert S.W., Takarangi M.K.T. (2010). Cognitive-behavioural Rehabilitation of High-risk Violent Offenders: Investigating Treatment Change with Explicit and Implicit Measures of Cognition. Applied Cognitive Psychology, 24(3), 437-449.

37. Polaschek D.L.L., Collie R.M., Walkey F.H. (2004). Criminal Attitudes to Violence: Development and Preliminary Validation of a Scale for Male Prisoners. Aggressive behaviour, 30(6), 484-503.

38. Qiu C., Zhao L., Liu X., Yu Y., Meng Y., Wu J., Luo Y., Lai L., Wen F., Lin D., Wang X., Zhang X., Ma X. (2014). Role of Psychosocial Factors and Serotonin Transporter Genotype in Male Adolescent Criminal Activity. Asia-Pacific Psychiatry, 6(3), 284-291.

39. Riedel M., Welsh W. (2011). Criminal Violence. Patterns, Causes and Prevention. New York: Oxford University Press.

40. Robertson K., Murachver T. (2007). Correlates of Partner Violence for Incarcerated Women and Men. Journal of Interpersonal Violence, 22(5), 639-655. Retrieved from http://citeseerx.ist.psu.edu/viewdoc/download?doi=10.1.1.930.9031\&rep=rep1\&type=pdf

41. Scott S., Babcock J.C. (2009). Attachment as a Moderator Between Intimate Partner Violence and PTSD Symptoms. Journal of Family Violence, 25(1), 1-9.

42. Shaver P.R., Balsky J., Brennan K.A. (2000) The Adult Attachment Interview and Self- reports of Romantic Attachment: Associations across Domains and Methods. Personal relationships, 7(1), 25-43.

43. Shemmings D. (2005). Adult Attachment Theory. Norwich: Social Work Monographs.

44. Simane-Vigante L., Plotka I., Blumenau N. (2015). Research of Attitudes towards Criminal Violence with Implicit and Explicit Measures of Cognition. Journal of Education, Psychology and Social Sciences, 3(2), 72-77. Retrieved from

https://www.academia.edu/19778700/Research_of_Attitudes_Towards_Criminal_Violence_with_Implicit_ and_Explicit_Measures_of_Cognition

45. Snowden R.J., Gray N.S., Smith J., Morris M., MacCulloch M.J. (2004). Implicit Affective Association to Violence in Psychopathic Murderers. The Journal of Forensic Psychiatry and Psychology, 15(4), 620-641.

Retrieved from http://psych.cf.ac.uk/home2/snowden/2004_JFPP_Snowdenetal.pdf

46. Tellegen A. (1985). Structures of Mood and Personality and Their Relevance to Assessing Anxiety with an Emphasis on Self-report. In A. Tuma, J. Maser (Eds.), Anxiety and the Anxiety Disorders. Hillsdale, NJ: Erlbaum, 681-706.

47. Tucker S.J., Anders S.L. (1998) Adult Attachment Style and Nonverbal Closeness in Dating Couples. Journal of nonverbal behaviour, 22(2), 109-124.

48. Woodworth M., Porter S. (2002). In Cold Blood: Characteristics of Criminal Homicides as a Function of Psychopathy. Journal of Abnormal Psychology, 111(3), 436-445. 